\title{
Non-equilibrium transformation of titanate nanowires to nanotubes upon mechanochemical activation
}

\author{
Gábor Kozma, ${ }^{a}$ Zoltán Kónya $^{a, b}$ and Ákos Kukovecz ${ }^{a, c, *}$ \\ Received (in $X X X, X X X) X$ th $X X X X X X X X X 20 X X$, Accepted Xth $X X X X X X X X X 20 X X$ \\ ${ }_{5}$ DOI: $10.1039 / \mathrm{b000000x}$
}

We report on finding the missing piece for the puzzle of interconnected titanate nanostructure reactions: converting titanate nanowires into titanate nanotubes using mechanochemical activation in a planetary ball mill. The best 10 conversion is achieved with individual ball impact energy of $11 \mathrm{~mJ} / \mathrm{hit}$ and a cumulative milling energy of $892 \mathrm{~J} / \mathrm{g}$.

The field of one dimensional (1D) titanate nanostructure research has matured into an application oriented one by now ${ }^{1}$. One of the driving forces behind this is that the transformation pathways 15 between the various titanate species during hydrothermal synthesis have been mapped and a consensus on the formation mechanism $^{2}$ and characterization ambiguities ${ }^{3}$ has been reached. However, experimental evidence about the actual realization of all possible reactions in the $1 \mathrm{D}$ titanate nanostructure system is 20 not yet available. The most important missing piece of the puzzle is the backwards transformation of titanate nanowires (TiONWs) into nanotubes (TiONTs) ${ }^{4}$, 5 . Titanate nanowires represent a very stable form of sodium trititanate. In fact, they are formed by the merger of titanate nanotubes to reduce the free energy of the

25 system. Earlier we have provided the experimental evidence for this ${ }^{6}$ and Bavykin et al. have demonstrated that the system gains approx. $20 \mathrm{~kJ} / \mathrm{mol}$ by the transformation ${ }^{7}$. The reverse reaction is not possible under the usual hydrothermal equilibrium conditions. However, it should be noted that the rearrangement of titanate 30 nanowires into anatase nanoshuttles under hydrothermal conditions has been reported by Wang et al. ${ }^{8}$.

Here we report on realizing the reverse reaction (titanate nanowire to nanotube conversion) by mechanochemical activation in a planetary ball mill. The construction of the 35 planetary ball mill makes high ball impact energies possible ${ }^{9,10}$. Therefore, very high local temperature and pressure are experienced by the material caught between a ball and the milling drum wall for a few microseconds, and then the system is rapidly quenched as the impact energy is dissipated to the milling matrix 40 and the drum. These conditions are suitable for non-equilibrium processing because they allow the system to be frozen into a high-energy state after impact activation ${ }^{11}$.

We performed five milling experiments on titanate nanowires. The starting $\mathrm{H}_{2} \mathrm{Ti}_{3} \mathrm{O}_{7}$ nanowire material was synthesized as 45 described earlier 6 and labeled "A". Samples "B" - "F" were milled for 15 minutes at increasing rotational speeds so that the individual hit energy increased from $1.2 \mathrm{~mJ} / \mathrm{hit}$ to $30.6 \mathrm{~mJ} / \mathrm{hit}$ and the cumulative energy transferred to the system increased from
$33 \mathrm{~J} / \mathrm{g}$ to $4130 \mathrm{~J} / \mathrm{g}$.

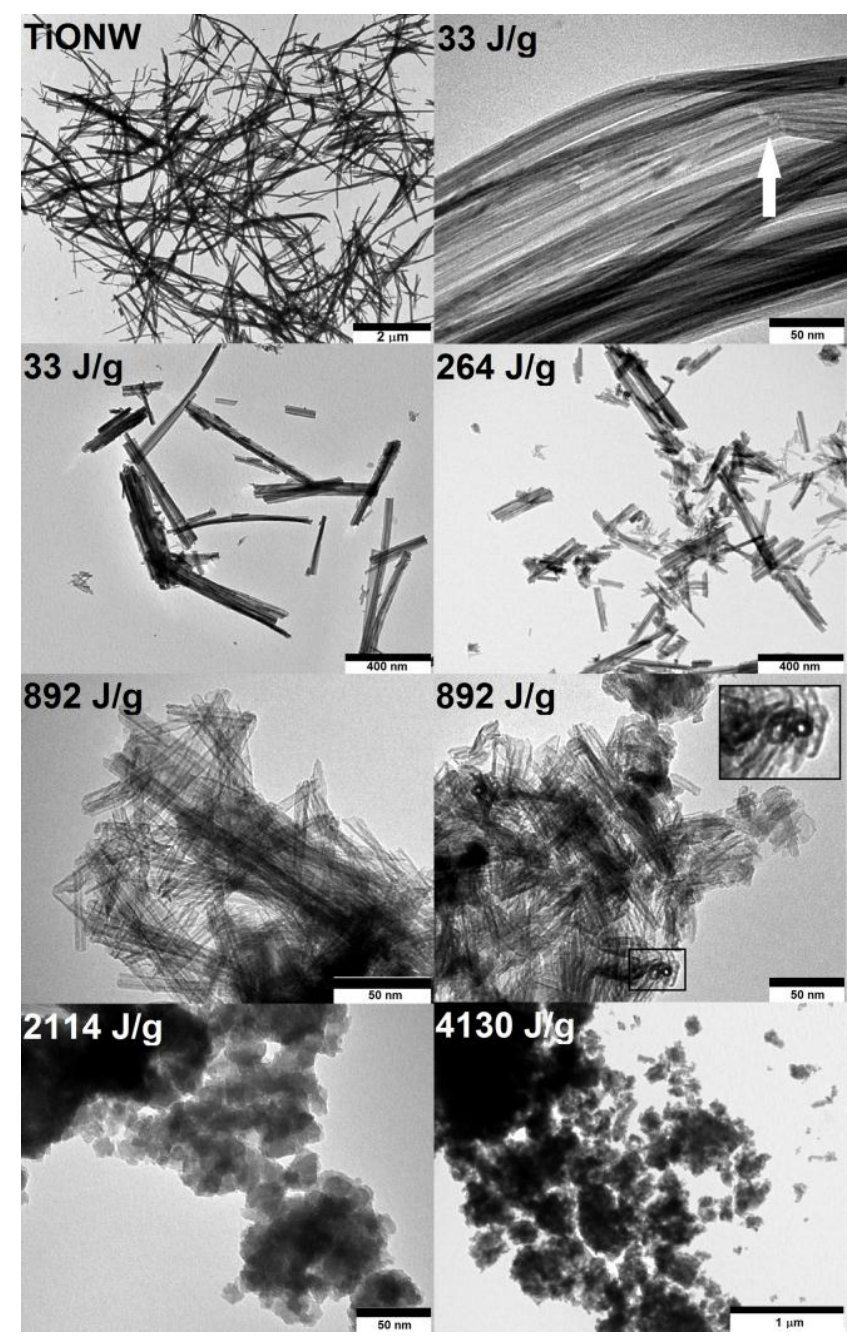

50

Figure 1. Characteristic TEM images of the starting titanate nanowires (top left) and milling products obtained at various cumulative milling energies. The inset in the $892 \mathrm{~J} / \mathrm{g}$ (right hand side) image provides a magnified view of the tubular cross55 section of the milling product.

As-synthesized titanate nanowires featured a diameter of 45-90 
$\mathrm{nm}$ and length of 1-5 micrometer, and their Transmission Electron Microscopy (TEM) appearance was identical to the well-known TiONW morphology (Figure 1, top left). Even the lowest milling energy ("B") was enough to loosen the structure of 5 the nanowires and break them into smaller fragments.

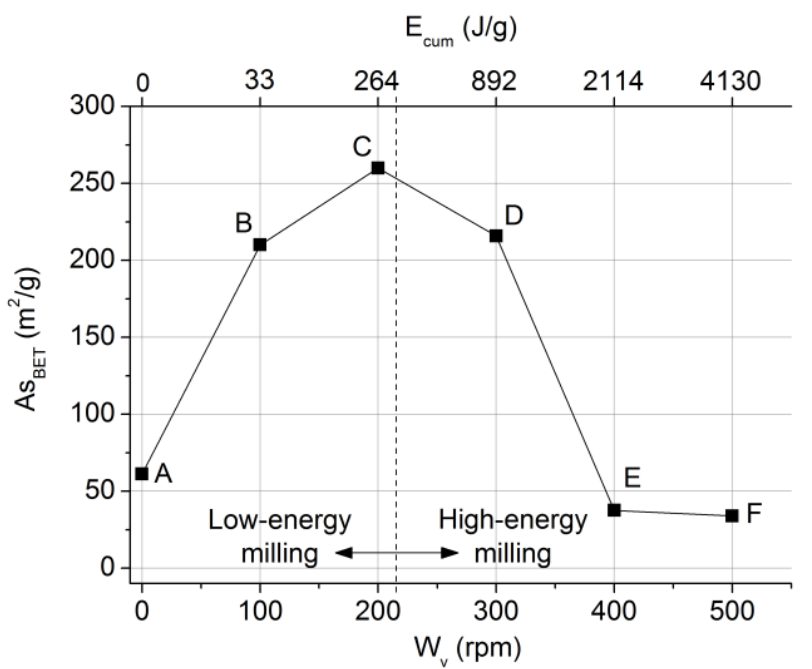

Figure 2. Specific surface area of the milled titanate nanowires as a function of the rotational speed of the planetary ball mill.

The white arrow in the top right image of Figure 1. indicates a 10 typical breakage point and the corresponding low resolution image depicts the resulting nanowire fragments measuring 100$680 \mathrm{~nm}$ in length and $18-50 \mathrm{~nm}$ in diameter. This means that the starting nanowires have broken into multiple pieces along their long axis but their thickness reduction was less characteristic at 15 this low milling energy. Increasing the cumulative milling energy to $264 \mathrm{~J} / \mathrm{g}$ resulted in shorter and thinner nanowire fragments (length $70-500 \mathrm{~nm}$, diameter $18-30 \mathrm{~nm}$ ) due to the larger number of hits. However, raising the impact energy to $11 \mathrm{~mJ} / \mathrm{hit}$ and the cumulative milling energy to $892 \mathrm{~J} / \mathrm{g}$ resulted in a product of a 20 very peculiar morphology as depicted in the third row TEM images in Figure 1. The observed fragments are not simply even shorter pieces of the same TiONW. Rather, they appear very similar to literature images of titanate nanotubes. Their typical length and outer diameter measure 40-80 nm and 5-8 nm, 25 respectively and they are open at both ends. The tubular structure is particularly well visible in the magnified image of a circular cross-section object crossing the focal plane of the TEM instrument shown in the inset (Figure 1, third row, right image). The tubular nanoobjects are replaced by agglomerates of isotropic 30 nanoparticles of $12-20 \mathrm{~nm}$ in diameter at cumulative energies above $2 \mathrm{~kJ} / \mathrm{g}$ (Figure 1, bottom row).

Specific surface area measurements depicted in Figure 2. allow more insight into the conversion process. The starting nanowires ("A") are characterized by an $\mathrm{As}_{\mathrm{BET}}=57 \mathrm{~m}^{2} / \mathrm{g}$ value which agrees 35 well with literature reports on TiONWs. As $200 \mathrm{~m}^{2} / \mathrm{g}$ for all samples milled with a cumulative energy below 1 $\mathrm{kJ} / \mathrm{g}$ because delamination of the titanate sheets from the large TiONW body makes previously hidden sheet faces available for nitrogen adsorption. The largest specific surface area $\left(260 \mathrm{~m}^{2} / \mathrm{g}\right)$ 40 belongs to the $264 \mathrm{~J} / \mathrm{g}$ sample which consists of the thinnest stripes. Samples "B" and "D" have smaller specific surface areas because the fragments of the $33 \mathrm{~J} / \mathrm{g}$ sample are somewhat thicker due to the lower milling energy, whereas the $892 \mathrm{~J} / \mathrm{g}$ sample consist of rolled-up nanotubes where a part of the sheet surface is 45 unavailable for adsorption again. The specific surface area of the isotropic nanoparticles obtained by milling above $2 \mathrm{~kJ} / \mathrm{g}$ is less than $50 \mathrm{~m}^{2} / \mathrm{g}$ because these samples are nonporous and their nitrogen adsorption capacity is determined by the open surface of the nanoparticle agglomerates.

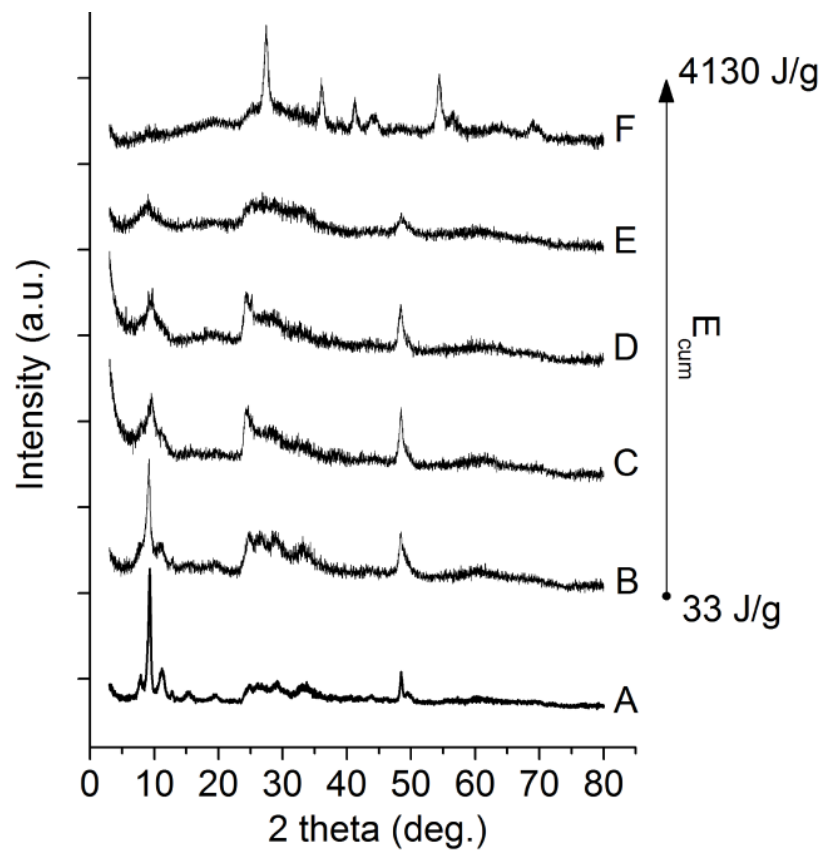

${ }_{50}$ Figure 3. XRD of the starting titanate nanowires ("A") and products obtained by increasing the milling energy.

The crystalline phase transformation of the material was characterized by powder X-ray diffractometry (XRD) as depicted 55 in Figure 3. The as-synthesized TiONWs ("A"), milled nanowire fragments ("B" and "C") and nanotubes ("D") have all exhibited the characteristic peaks at $9.6^{\circ}, 26.3^{\circ}$ and $49.6^{\circ}$ which are frequently used in the literature to identify titanate nanowires. Therefore, we now conclude that the original titanate nanowires 60 were transformed into titanate nanotubes in the planetary ball mill when the cumulative milling energy was $892 \mathrm{~J} / \mathrm{g}$. Sample "E" consists of isotropic nanoparticles of a titanate crystal structure according to the XRD, but loss of reflection intensity and peak broadening indicate that a partial amorphization process took ${ }_{65}$ place. Sample "F" is characterized by XRD peaks at $27.5^{\circ}, 36.2^{\circ}$, $41.3^{\circ}$ and $54.3^{\circ}$ which are clear indicators of a rutile crystal structure.

The following interpretation explains these findings. A high energy mechanical impact can transfer enough energy to a 70 titanate nanowire to delaminate smaller nanotube precursor sheets from it. Similar delamination processes were observed for titanate nanowires in solution under acidic conditions ${ }^{12}$ but have neither identified any nanotube products nor were ever reported for mechanical agitation until now. Here, the system is automatically 75 quenched microseconds after each impact in the planetary ball mill and therefore, the delaminated nanotube precursor sheets cannot reassemble into a titanate nanowire even though that 
would be thermodynamically favourable. Therefore, they roll up into short titanate nanotubes instead as suggested earlier for hydrothermal synthesis conditions of titanate ${ }^{13,14}$ and halloysite nanotubes ${ }^{15}$ as well as for intercalated kaolinite nanoscrolls ${ }^{16}$. 5 The delamination process can be initiated by ball impact energies as low as $1.2 \mathrm{~mJ} / \mathrm{hit}$, but the characteristic process at low energies is nanowire fragmenting along the long axis. Energies around 1 $\mathrm{kJ} / \mathrm{g}$ are sufficient to create individual titanate sheets which are able to roll up into nanotubes, whereas cumulative energies above

${ }_{10} 2 \mathrm{~kJ} / \mathrm{g}$ create a situation when the sufficiently large number of hits on the formed titanate nanotubes furthers their transformation. The nanotubes are ground into small, isotropic nanoparticles, then subsequent hits assist the recrystallization of these particles into the rutile phase confirming the findings of 15 Plodinec et al. ${ }^{17}$.

Summarizing, the main importance of the reported work is that it provides the first experimental evidence for the transformation of titanate nanowires into titanate nanotubes. We have shown that this reaction is possible in the highly non-equilibrium conditions 20 of a mechanochemical reactor and that careful energy control must be maintained so that the transformation can be stopped at the titanate nanotube stage, which is an intermediate phase en route the mechanically initiated transformation of titanate nanowires into isotropic rutile nanoparticles.

\section{${ }_{25}$ Notes and references}

${ }^{a}$ Department of Applied and Environmental Chemistry, University of Szeged, Rerrich B. ter 1, 6720 Szeged, Hungary. Fax: 3662544 619; Tel: 3662544 620;E-mail: kozmag@chem.u-szeged.hu

${ }^{b}$ MTA-SZTE Reaction Kinetics and Surface Chemistry Research Group.

30 Rerrich B. ter 1, 6720 Szeged, Hungary. Fax: 3662544 619; Tel: 36

62544 620; E-mail: konya@chem.u-szeged.hu

${ }^{c}$ MTA-SZTE "Lendület" Porous Nanocomposites Research Group.

Rerrich B. ter 1, 6720 Szeged, Hungary. Fax: 3662544 619; Tel: 36

62544 620;E-mail:kakos@chem.u-szeged.hu

$\uparrow$ Electronic Supplementary Information (ESI) available: Details of the experimental procedures, milling energy calculation method. See DOI: $10.1039 / \mathrm{b} 000000 \mathrm{x} /$

40 The financial support of the TÁMOP-4.2.2.A-11/1/KONV-2012-0047, TÁMOP-4.2.2.A-11/1/KONV-2012-0060 and OTKA K 83889 projects is acknowledged.

1. D. V. Bavykin and F. C. Walsh, Eur. J. Inorg. Chem., 2009, 2009, 97745997

2. A. L. Papa, N. Millot, L. Saviot, R. Chassagnon and O. Heintz, J. Phys. Chem. C, 2009, 113, 12682-12689.

3. S. J. Kim, Y. U. Yun, H. J. Oh, S. H. Hong, C. A. Roberts, K. Routray and I. E. Wachs, Journal of Physical Chemistry Letters, 2010,

$50 \quad$ 1, 130-135.

4.D. V. Bavykin, A. N. Kulak and F. C. Walsh, Langmuir, 2011, 27, 5644-5649.

5. D. Wu, J. Liu, X. N. Zhao, A. D. Li, Y. F. Chen and N. B. Ming, Chem. Mat., 2006, 18, 547-553.

55 6. E. Horvath, A. Kukovecz, Z. Konya and I. Kiricsi, Chem. Mat., 2007, 19, 927-931.

7.D. V. Bavykin, A. N. Kulak and F. C. Walsh, Cryst. Growth Des., 2010, 10, 4421-4427.
8.H. K. Wang, W. Shao, F. Gu, L. Zhang, M. K. Lu and C. Z. Li, $60 \quad$ Inorganic Chemistry, 2009, 48, 9732-9736.

9. L. Q. Zhou, P. M. Vilarinho and J. L. Baptista, Journal of the European Ceramic Society, 1999, 19, 2015-2020.

10. N. Pavlovic, V. Koval, J. Dusza and V. V. Srdic, Ceramics International, 2011, 37, 487-492.

$6511 . \quad$ C. Suryanarayana, Progress in Materials Science, 2001, 46, 1184

12. B. Schurer, M. J. Elser, A. Sternig, W. Peukert and O. Diwald, J. Phys. Chem. C, 2011, 115, 12381-12387.

13. G. Mogilevsky, Q. Chen, A. Kleinhammes and Y. Wu, 70 Chemical Physics Letters, 2008, 460, 517-520.

14. A. Nakahira, T. Kubo and C. Numako, Inorganic Chemistry, 2010, 49, 5845-5852.

15. R. D. White, D. V. Bavykin and F. C. Walsh, J. Phys. Chem. C, 2012, 116, 8824-8833.

$7516 . \quad$ Y. Kuroda, K. Ito, K. Itabashi and K. Kuroda, Langmuir, 2011, 27, 2028-2035.

17. M. Plodinec, I. Friscic, D. Ivekovic, N. Tomasic, D. S. Su, J. Zhang and A. Gajovic, Journal of Alloys and Compounds, 2010, 499, 113-120. 